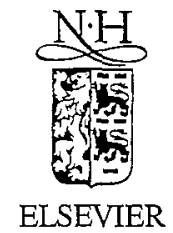

Journal of Non-Crystalline Solids 191 (1995) 1-16

\title{
Polymeric-silica-based sols for membrane modification applications: sol-gel synthesis and characterization with SAXS
}

\author{
R.S.A. de Lange ${ }^{1}$, J.H.A. Hekkink, K. Keizer ${ }^{*}$, A.J. Burggraaf \\ University of Twente, Faculty of Chemical Technology, Laboratory for Inorganic Chemistry, Materials Science and Catalysis, PO Box 217 , \\ 7500 AE Enschede, The Netherlands.
}

Received 17 August 1994; revised manuscript received 6 April 1995

\begin{abstract}
Polymeric $\mathrm{SiO}_{2}$ and binary $\mathrm{SiO}_{2} / \mathrm{TiO}_{2}, \mathrm{SiO}_{2} / \mathrm{ZrO}_{2}$ and $\mathrm{SiO}_{2} / \mathrm{Al}_{2} \mathrm{O}_{3}$ sols, for ceramic membrane modification applications, have been prepared by acid-catalyzed hydrolysis and condensation of alkoxides in alcohol. The sols were characterized with small angle X-ray scattering, using synchrotron radiation. Directly after synthesis, the sols were found to consist of weakly branched polymeric structures with typical fractal dimensions of around 1.5 and radii of gyration of $\approx 2$ $\mathrm{nm}$. The aggregation for silica sols obeys the tip-to-tip cluster-cluster aggregation model in the initial stages. Prehydrolysis of TEOS was found to be the best method to synthesize polymeric binary systems. Based on an analysis of film formation from sols consisting of weakly branched polymers, it is expected that consolidation of these polymers will result in microporous materials.
\end{abstract}

\section{Introduction}

Improvement of the gas separation properties of mesoporous membranes by pore size reduction to the micropore (IUPAC definition [1], $r_{\text {pore }}<1 \mathrm{~nm}$ ) range, can be obtained successfully by sol-gel modification with polymeric inorganic sols. A strong increase of separation factors, which are mainly governed by Knudsen diffusion for mesoporous membranes $\left(\alpha_{\text {ideal }}=\left(\mathrm{M}_{\mathrm{A}} / \mathrm{M}_{\mathrm{B}}\right)^{1 / 2}\right)$, to molecular sieve-like separation factors, have been reported [2-7].

\footnotetext{
${ }^{*}$ Corresponding author. Tel: $+31-53899111$. Telefax: $+31-53$ 356024.

${ }^{1}$ Present address: Flexovit Produktie bv, Research Department Abrasive Products, PO Box 10, 7150 AA Eibergen, The Netherlands.
}

In this paper, the sol synthesis and characterization are described of inorganic $\mathrm{SiO}_{2}, \mathrm{SiO}_{2} / \mathrm{TiO}_{2}$, $\mathrm{SiO}_{2} / \mathrm{Al}_{2} \mathrm{O}_{3}$ and $\mathrm{SiO}_{2} / \mathrm{ZrO}_{2}$ polymeric sols for membrane modification applications. The thermal stability of $\mathrm{SiO}_{2}$ is high, but the chemical stability at high temperatures in the presence of water is poor [8]. The attack of water breaks $\mathrm{Si}-\mathrm{O}-\mathrm{Si}$ bonds, resulting in the formation of surface hydroxyls ( $\mathrm{Si}-$ $\mathrm{OH})$. Incorporation of a second component, such as $\mathrm{Al}_{2} \mathrm{O}_{3}, \mathrm{TiO}_{2}$ and especially $\mathrm{ZrO}_{2}$, in glass has proven to improve the chemical stability. Analogous to glasses, the incorporation of these binary components in sol-gel-derived silica might have the same effect.

By using small angle X-ray scattering (SAXS), the influence is investigated of synthesis conditions such as water content and acid content on the struc- 
ture of the polymeric sols. Also the structural evolution of sols as function of sol age is followed. Some important conclusions are made concerning the structural evolution of the sols and the differences between binary sols compared with silica sols. The results obtained are also compared with aggregation models from literature.

The sol-gel process involves the hydrolysis (1) and condensation (2) of alkoxides:

$$
\begin{aligned}
& \equiv \mathrm{Si}-\mathrm{OR}+\mathrm{H}_{2} \mathrm{O} \rightleftarrows \equiv \mathrm{Si}-\mathrm{OH}+\mathrm{ROH}, \\
& \equiv \mathrm{Si}-\mathrm{OR}+\mathrm{HO}-\mathrm{Si} \equiv \rightleftarrows \equiv \mathrm{Si}-\mathrm{O}-\mathrm{Si} \equiv+\mathrm{ROH} .
\end{aligned}
$$

By controlling the synthesis conditions carefully, the sol morphology can be directed towards weakly branched polymeric systems or to particulate systems [9]. Control of the relative rates of hydrolysis and (poly)condensation, and the respective mechanisms of these reactions are the main tools for this difference [10]. Important process parameters are the water content, the solvent, the catalyst used (acid or base) and its concentration and the type of alkoxide used. The reactivities of transition metal alkoxides are considerably higher than for silicon alkoxides, even factors of $10^{5}$ have been reported [11]. Therefore, care has to be taken in the synthesis of binary materials to avoid homo-condensation. A commonly used strategy to avoid this is by using a prehydrolysis process: the slowest reacting alkoxide is prehydrolyzed prior to the addition of the second, fast reacting, alkoxide.

For the formation of microporous consolidated films, it is believed that weakly branched polymeric systems, with fractal dimensions $D_{\mathrm{f}}<2$ are preferred [12]. The concept behind microporous membrane formation is a certain extent of interpenetration of weakly branched polymers. This picture, however, is for most practical situations not complete, since during consolidation (drying) further condensation reactions may take place. The extent in which this happens depends on both the sol reactivity and the relative rates of consolidation (evaporation) and condensation.

The synthesis conditions which lead to these weakly branched systems involve the use of an acid catalyst, where $\mathrm{pH} \ll 2.2$ (iso-electric point of silica), and the use of low to moderate water content ([water]/[alkoxide] $<10$ ). Hydrolysis (1) then takes place via a fast protonation of the alkoxide, followed by an attack of water, resulting in the substitution of the alkoxy-group with an hydroxyl group. Protonation becomes slower when more hydroxyls are present, since hydroxyl groups are stronger electronwithdrawing, which causes a lower stability of the protonated alkoxide. The hydrolysis rate will therefore decrease with the extent of $\mathrm{OH}$ substitution. Acid-catalyzed condensation proceeds analogously, where a protonated silanol species is attacked by water. The condensation reaction rate decreases with the number of condensed Si-O-Si groups.

Condensation reactions under acid-catalyzed conditions are much slower than hydrolysis reactions, and start generally when hydrolysis is complete. As a consequence, a large amount of hydrolyzed species is present at the moment condensation becomes significant. Since the condensation reactions then take place between individual hydrolyzed species throughout the reaction vessel, the aggregation can be regarded as a cluster-cluster aggregation process [9]. The general trend is therefore that acid-catalyzed reaction processes lead to weakly branched structures.

Small angle X-ray scattering, using synchrotron radiation, is an excellent technique to characterize these sols. When sols possess a fractal geometry, the fractal dimension and a radius, $R_{g},{ }^{2}$ can be determined from a plot of $\log (I)$ versus $\log (Q)$, where $I$ is the scattered intensity and $Q$ is the scattering vector defined by

$Q=(4 \pi / \lambda) \sin (\theta)$,

where $\lambda$ is the wave length and $2 \theta$ is the scattering angle. If $\xi$ and $r_{0}$ are the upper and lower cut-off length of the fractal structure (corresponding with the size of the fractal and the size of the primary building unit), the log-log plot for fractal systems can be divided in three regions [13]:

(i) The so-called 'Guinier region', $Q \ll 1 / \xi$, where, provided the system is diluted and monodis-

\footnotetext{
${ }^{2}$ This radius is often referred to as the Guinier radius, although in a strict sense this may not always be correct.
} 
perse, $I(Q)$ can be expressed by Guinier's approximation:

$I(Q) \propto \exp \left(-\frac{Q^{2} R_{\mathrm{g}}^{2}}{3}\right)(Q \ll 1 / \xi)$,

where $R_{\mathrm{g}}$ is the so-called Guinier radius. For most practical systems, however, this approximation is not allowed. For instance, for diluted, polydisperse systems, Eq. (4) will yield an average of the radius of gyration.

(ii) The intermediate region or 'fractal region' $\left(1 / \xi \ll Q \ll 1 / r_{0}\right)$, where the intensity can be described by a power-law, the fractal dimension can be determined from the slope $\left(-D_{\mathrm{f}}\right)$ :

$I(Q) \propto Q^{-D_{t}},(1 / \xi) \ll Q \ll\left(1 / r_{0}\right)$.

(iii) At large scattering vectors $\left(Q \gg 1 / \mathbf{r}_{0}\right)$, the intensity will follow Porod's law, resulting in a slope -4 for smooth particles or building blocks.

From the crossover points in the scattering regions, which take place at $Q \approx 1 / \xi$ and $Q \approx 1 / r_{0}$, the sizes of the respective scattering units $\left(\xi\left(\approx R_{\mathrm{g}}\right)\right.$ and $r_{0}$ ) can be estimated. The radius of gyration, $R_{\mathrm{g}}$, of the polymeric structures can be determined from the crossover point in the log-log spectra by assuming $1 / \xi \approx 1 / R_{\mathrm{g}}$. However, one should bear in mind that, if the concentration of the polymers is high, and entanglement occurs, an underestimate of $R_{\mathrm{g}}$ is determined, since this parameter is defined only for systems in which the interparticle interference is negligible [9].

\section{Experimental}

\subsection{Sol-gel synthesis}

\subsubsection{Silica sol synthesis}

Polymeric silica sols were prepared by acid-catalyzed $\left(\mathrm{HNO}_{3}\right.$, Merck, p.a. grade) hydrolysis and condensation of tetraethylorthosilicate $\left(\mathrm{Si}(\mathrm{OEt})_{4}\right.$, TEOS, Merck p.a. grade) in alcohol (ethanol, Merck, p.a. grade). A mixture of acid and water was carefully added, using a dropping funnel, to a mixture of ethanol and TEOS under vigorous stirring. The reaction mixture was then refluxed for $3 \mathrm{~h}$ at $80^{\circ} \mathrm{C}$ under stirring. Molar ratios water/TEOS, alcohol/TEOS
Table 1

Composition of standard silica polymeric sol $\left(\mathrm{StSiO}_{2}\right)$

\begin{tabular}{lllll}
\hline & TEOS & $\begin{array}{l}\mathrm{H}_{2} \mathrm{O} \\
\left(r_{\mathrm{w}}\right)\end{array}$ & $\begin{array}{l}\mathrm{C}_{2} \mathrm{H}_{5} \mathrm{OH} \\
\left(r_{\text {alcohol }}\right)\end{array}$ & $\begin{array}{l}\mathrm{HNO}_{3} \\
(1 \mathrm{M}) \\
\left(r_{\mathrm{H}+}\right)\end{array}$ \\
\hline mol: & 0.094 & 0.6 & 0.36 & 0.008 \\
mol ratio (X/TEOS): & $(1)$ & $(6.4)$ & $(3.8)$ & $(0.085)$ \\
\hline
\end{tabular}

and acid/TEOS are abbreviated as $r_{\mathrm{w}}, r_{\mathrm{alcohol}}$ and $r_{\mathrm{H}+}$, respectively. The standard composition (in mol as well as mol ratio to TEOS) of the reaction mixtures is given in Table 1 .

\subsubsection{Binary sol synthesis}

Binary $\mathrm{SiO}_{2}$-based sols are prepared using TEOS, with titanium isopropoxide $\left(\mathrm{Ti}\left(\mathrm{O}^{\mathrm{i}} \mathrm{Pr}\right)_{4}\right.$, Merck, p.a. grade) or titanium-n-butoxide $\left(\mathrm{Ti}\left(\mathrm{O}^{\mathrm{n}} \mathrm{Bu}\right)_{4}\right.$, Merck, p.a. grade), zirconium-n-butoxide-n-butanol complex $\left(\mathrm{Zr}\left(\mathrm{O}^{\mathrm{n} B u}\right)_{4}-{ }^{\mathrm{n}} \mathrm{BuOH}\right.$, Alfa, p.a. grade $)$ and aluminium-di-sec-butoxide-acetoacetic ester chelate $\left(\mathrm{Al}\left(\mathrm{O}^{s} \mathrm{Bu}\right)_{2}\right.$-etac, Alfa, p.a. grade) as alkoxides for $\mathrm{SiO}_{2} / \mathrm{TiO}_{2}, \mathrm{SiO}_{2} / \mathrm{ZrO}_{2}$ and $\mathrm{SiO}_{2} / \mathrm{Al}_{2} \mathrm{O}_{3}$, respectively. Alcohols are used as solvent: (n-butanol (Merck, p.a. grade), ethanol (Merck p.a. grade), or iso-propanol (Merck, p.a. grade)). In Fig. 1 the reaction scheme for the synthesis of binary sols is given. Binary sols are abbreviated as $\operatorname{SiM} x x$, where $M$ is

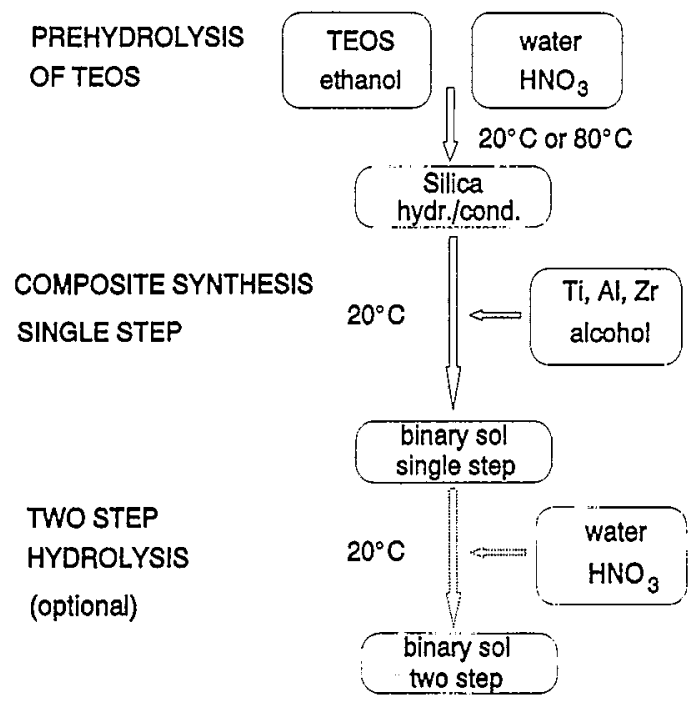

Fig. 1. Synthesis of binary polymeric sols by single-step and two-step hydrolysis. 
Table 2

Standard reaction conditions of binary sols

\begin{tabular}{|c|c|c|c|c|c|}
\hline \multirow[t]{2}{*}{$\overline{\text { System }}$} & \multicolumn{2}{|c|}{ Prehydrolysis } & \multicolumn{3}{|l|}{ Step 2} \\
\hline & $T\left({ }^{\circ} \mathrm{C}\right)$ & time (h) & $T\left({ }^{\circ} \mathrm{C}\right)$ & time $(\mathrm{h})$ & extra $\mathrm{H}_{2} \mathrm{O} / \mathrm{HNO}_{3}$ \\
\hline SiTi10/30 & 80 & 2.5 & 20 & 2 & no \\
\hline SiTi10, 2 step & 80 & 2.5 & 20 & 2 & yes \\
\hline \multicolumn{6}{|l|}{ SiTiloX } \\
\hline $\mathrm{Si}$ & 80 & 2 & 20 & 0.5 & no \\
\hline $\mathrm{Ti}$ & 20 & 0.5 & & & \\
\hline $\mathrm{SiZr10/30}$ & 20 & 3 & 20 & 3 & no \\
\hline $\operatorname{SiZr} 10,2$ step & 20 & 3 & 20 & 3 & yes \\
\hline SiAllo & 20 & 1.5 & 20 & 0.5 & no \\
\hline
\end{tabular}

$X$, Separate prehydrolysis of TEOS and $\mathrm{Ti}\left(\mathrm{O}^{\mathrm{i} P r}\right)_{4}$.

the second component and $x x$ is the molar percentage based on $\mathrm{MO}_{y} / \mathrm{SiO}_{2}$. The conditions, temperature and reaction time, for the synthesis of the binary sols are given in Table 2. The compositions (mol and molar ratio $\mathrm{X} / \mathrm{TEOS}$ ) are listed in Table 3.

Three synthesis routes have been used.

(A) Single-step prehydrolysis, which is the main route for the synthesis of binary $\mathrm{SiO}_{2} / \mathrm{TiO}_{2}$, $\mathrm{SiO}_{2} / \mathrm{ZrO}_{2}$ and $\mathrm{SiO}_{2} / \mathrm{Al}_{2} \mathrm{O}_{3}$ sols. Prehydrolysis of TEOS is followed by the addition of respectively the $\mathrm{Ti}, \mathrm{Zr}$ or $\mathrm{Al}$ alkoxide in alcohol.

(B) Two-step hydrolysis, for the synthesis of $\mathrm{SiO}_{2} / \mathrm{TiO}_{2}$ and $\mathrm{SiO}_{2} / \mathrm{ZrO}_{2}$ sols is a modification of the prehydrolysis process in the sense that it incorporates a second addition of water and acid after the addition, and followed by reaction for $2 \mathrm{~h}$, of the titanium or zirconium alkoxide.

(C) Separate prehydrolysis followed by mixing of sols; TEOS and titanium isopropoxide are prehydrolyzed separately and subsequently mixed to form a binary sol.

In Table 3 the total amount of each reactant (in $\mathrm{mol}$ ) is given for each sample for both the (pre)-hydrolysis step and the binary step (addition of $\mathrm{Ti}, \mathrm{Zr}$ or $\mathrm{Al}$ alkoxide). For the (pre)-hydrolysis step and the composite step, the alcohol used under standard conditions is ethanol and butanol, respectively. The molar ratios (in parentheses) are given based on the amount TEOS.

For a given sample, for example SiTi10-2 step,

Table 3

Standard composition (mol ratio) of binary sols

\begin{tabular}{|c|c|c|c|c|c|c|}
\hline \multirow[t]{2}{*}{ Sample code } & \multicolumn{4}{|c|}{ (Pre)-hydrolysis } & \multicolumn{2}{|l|}{ Composite step } \\
\hline & TEOS & $\mathrm{C}_{2} \mathrm{H}_{5} \mathrm{OH}$ & $\mathrm{H}_{2} \mathrm{O}$ & $\mathrm{HNO}_{3}$ & M alkoxide & $\mathrm{BuOH}$ \\
\hline SiTi10 & $0.094(1)$ & $0.36(3.8)$ & $0.096(1)$ & $0.008(0.085)$ & $0.01^{a}(0.11)$ & $0.23(2.5)$ \\
\hline $\begin{array}{l}\text { SiTi10, 2-step } \\
\text { 2-step }\end{array}$ & $0.094(1)$ & $0.36(3.8)$ & $\begin{array}{l}0.107(1.14) \\
0.6^{c}(6.4)\end{array}$ & $\begin{array}{l}0.002^{(0.021)} \\
0.008^{c}(0.085)\end{array}$ & $0.01^{a}(0.11)$ & $1.42^{b}(15.1)$ \\
\hline $\begin{array}{l}\text { SiTi10X } \\
\text { silica }\end{array}$ & $0.094(1)$ & $0.36(3.8)$ & $0.43(4.6)$ & $0.008(0.085)$ & - & . \\
\hline titania & $0.051(1)$ & $1.29(25.2)$ & $0.1(2.0)$ & $0.004(0.008)$ & - & - \\
\hline SiTi30 & $0.094(1)$ & $0.36(3.8)$ & $0.096(1)$ & $0.008(0.085)$ & $0.038^{a}(0.43)$ & $0.13(1.4)$ \\
\hline SiZrlo & $0.094(1)$ & $0.36(3.8)$ & $0.096(1)$ & $0.008(0.085)$ & $0.01(0.11)$ & $0.23(2.5)$ \\
\hline $\begin{array}{l}\text { SiZr10, 2-step } \\
\text { 2-step }\end{array}$ & $0.094(1)$ & $\begin{array}{l}0.36(3.8) \\
0.57^{c}(6.1)\end{array}$ & $\begin{array}{l}0.096(1) \\
0.144^{c}(1.5)\end{array}$ & $\begin{array}{l}0.008(0.085) \\
0.012^{c}(0.128)\end{array}$ & $0.01(0.11)$ & $0.23(2.5)$ \\
\hline $\mathrm{SiZ} 30$ & $0.094(1)$ & $0.36(3.8)$ & $0.096(1)$ & $0.008(0.085)$ & $0.04(0.43)$ & $0.07(0.76)$ \\
\hline SiAllo & $0.094(1)$ & $0.27^{\mathrm{d}}(2.9)$ & $0.17(1.8)$ & $0.016(0.17)$ & $0.007(0.1)$ & $1.3^{\mathrm{d}}(13.8)$ \\
\hline
\end{tabular}

${ }^{a} \mathrm{Ti}\left(\mathrm{O}^{\mathrm{n}} \mathrm{Bu}\right)_{4}$ as alkoxide. ${ }^{\mathrm{b}}$ ethanol. ${ }^{\mathrm{c}}$ Total amount after second hydrolysis step. ${ }^{d}$ iso-propanol. 
the composition of the reaction solution in the prehydrolysis step is given in columns 2-5 $(0.094 \mathrm{~mol}$ TEOS, $0.36 \mathrm{~mol}$ ethanol, $0.107 \mathrm{~mol}$ water and 0.002 mol $\mathrm{HNO}_{3}$ ). The composition of the solution of the Ti alkoxide is given in columns 6 and 7. In this case $\mathrm{Ti}\left(\mathrm{O}^{\mathrm{n}} \mathrm{Bu}\right)_{4}(0.01 \mathrm{~mol})$ is used as alkoxide and, contrary to the standard conditions, ethanol $(1.42 \mathrm{~mol})$ is used as alcohol. The molar ratios of the second hydrolysis step are given in the second row belonging to this sample. Only a solution of water and acid is added; the total amount after the second hydrolysis step is given $\left(0.6 \mathrm{~mol}\right.$ water and $\left.0.085 \mathrm{~mol} \mathrm{HNO}_{3}\right)$.

SiTi10X is prepared by mixing of separately prehydrolyzed sols. The silica sol was prepared as described before, with the exact conditions and composition given in Tables 1 and 3 (SiTi10X, Si). The titania sol (SiTi10X, Ti, molar ratios based on $\left.\mathrm{Ti}\left(\mathrm{O}^{\mathrm{i}} \mathrm{Pr}\right)_{4}\right)$ was prepared by careful addition of a solution of water and acid in ethanol (half of the total amount ethanol) to the ethanol diluted (second half of the ethanol amount) titanium propoxide. Both sols were diluted again with ethanol (1:1 by volume) and a binary sol was prepared by careful addition (using a dropping funnel) of the diluted TEOS polymeric solution to the diluted titania sol. The amount of titania sol was adjusted to result in a $\mathrm{SiO}_{2} / \mathrm{TiO}_{2}$ sol with $10 \mathrm{~mol} \% \mathrm{TiO}_{2}$.

The different conditions and compositions for the binary sols have been developed based on two criteria: (i) from the technical view point of membrane formation, gelation during synthesis has to be avoided, and (ii) microporosity and high porosity had to be obtained for the consolidated and calcined non-supported films $[6,14]$.

\subsubsection{Sol handling for SAXS experiments}

Prepared samples for SAXS experiments were kept at room temperature in closed glass containers of 5-20 ml, with approximately $20 \mathrm{vol} \%$ ambient air above the liquid level. The age of the samples varies from freshly prepared to maximum 50 days.

\subsection{Small angle $X$-ray scattering}

Small angle X-ray scattering experiments were performed using synchrotron radiation (X-ray wavelength $\lambda=1.54 \AA$ ) at the Non-Crystalline Diffraction beamline 8.2 of the SERC Synchrotron Radia- tion Source (SRS), Daresbury (UK) [15]. The scattered X-ray intensities were recorded using a quadrant detector. With camera lengths of 4 and $0.7 \mathrm{~m}$, $Q$-ranges of approximately $0.009-0.212 \AA^{-1}$ and 0.025-0.809 $\AA^{-1}$ could be measured, respectively. The detector position was calibrated for each camera length with the diffraction pattern of wet rat tail collagen (repeat distance $d=670 \AA$ ). Samples were mounted in brass cells with mylar windows. Spacers with thickness of $\approx 1$ and $\approx 2 \mathrm{~mm}$ were used to optimize the path length of the X-rays through the sample, which is a compromise between absorption and scattering intensity [16]. Data acquisition times are in the order of $5 \mathrm{~min}$ in order to obtain sufficiently high signal to noise ratios.

The raw data were first corrected for decay of beam intensity and detector sensitivity by normalization with respectively incident X-ray intensity and detector response function [17]. Second, data correction for background and parasitic scattering which originated from the solvent, mylar windows and slits was performed, using the fractal region [18], where $I(Q)$ has a $Q^{-D_{\mathrm{f}}}$ dependence according to

$I(Q)=\left(a / Q^{D_{i}}\right)+B$,

where $a$ is a constant and the value of background $B$ can be minimized by plotting $I(Q)$ versus $Q^{-D_{i}} . B$, given by the intercept, is adjusted by background substraction [16].

\section{Results}

\subsection{Polymeric silica sols with standard composition.}

\subsubsection{Structural evolution of standard silica sols during synthesis.}

During synthesis experiments of silica under standard conditions $\left(3 \mathrm{~h}\right.$ reaction at $80^{\circ} \mathrm{C}$ ), samples were taken at intervals of $1 \mathrm{~h}$. In the first hour of the hydrolysis and condensation process of the polymeric solution, no scattering was detected. After about $1 \mathrm{~h}$ of reaction, however, the fractal regions became visible in the spectra. The SAXS spectra show an increase of the $Q$-range where $I(Q)$ follows the $Q^{-D_{\mathrm{f}}}$ law during the hydrolysis process. A typical spectrum, of standard silica sol A after $3 \mathrm{~h}$, is given in Fig. 2. As can be seen, the spectrum follows 


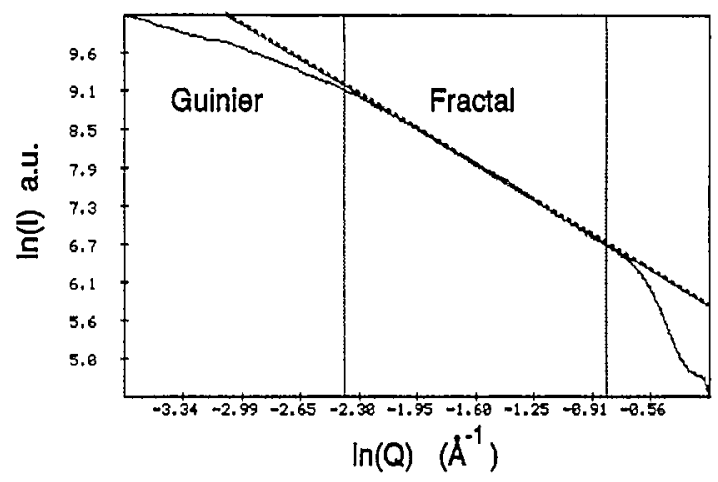

Fig. 2. SAXS spectrum of sol A after $3 \mathrm{~h}$ of reaction. $D_{\mathrm{f}}=1.47 \pm$ $0.07, R_{\mathrm{g}}=1.4 \pm 0.2 \mathrm{~nm}$, camera length $=0.7 \mathrm{~m}$.

the theoretical expected shape reasonably well. The fractal dimension was calculated with linear regression analysis in the fractal region between the two vertical dotted lines; the experimental error in the calculation is about 0.07 for $D_{\mathrm{f}}$.

The radius of gyration was determined from the crossover point between fractal behaviour to the Guinier region. However, the spectrum is slightly concave at this point, and the transitions therefore are not sharp, which can be expected for a physical system consisting of a large number of scatterers. Since in most cases the Guinier region is almost linear on the scale used, the crossover point can be estimated using a linear fit of the Guinier region. Fitting between $\ln (Q)=-3.7$ and $=-2.99$ gives a straight line which results in an intersection at $\ln (Q)$ $=-2.64$. Then $Q=0.07136$, and $R_{\mathrm{g}}=1 / Q=1.4$ $\mathrm{nm}$. The reproducibility of this assessment has found to be in the order of $0.2 \mathrm{~nm}$.

Detailed analysis of the Porod region is not allowed, since the fitting procedure, which is performed for data in the fractal region, may not be correct for the Porod region. The $Q$-value at the transition point can therefore only be used to give an estimate of the upper value of $r_{0}$. This is $r_{0, \max } \approx 0.2$ nm.

The reproducibility of the calculation of $D_{\mathrm{f}}$ and $R_{\mathrm{g}}$ from a certain SAXS spectrum was good as stated before. The experimental error determined from duplicate experiments with sols prepared under identical conditions, however, is slightly higher and around 0.2 in the calculated $D_{\mathrm{f}}$ and maximum around $1 \mathrm{~nm}$ for $R_{\mathrm{g}}$ (see Figs. 3 and 4 ).

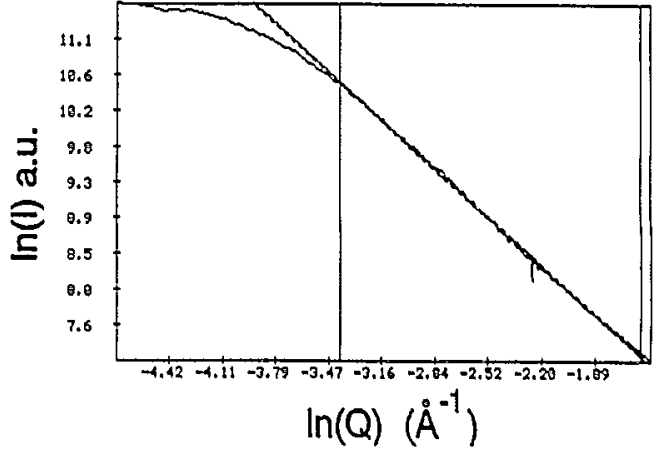

Fig. 3. SAXS spectrum of a 46-day-old silica sumple. Obtained with $4 \mathrm{~m}$ camera length. $D_{\mathrm{f}}=1.86 \pm 0.07, R_{\mathrm{g}}=4.1 \pm 0.2 \mathrm{~nm}$.

The results of three experiments with standard silica sols, where identical synthesis conditions are used, are summarized in Table 4; the samples were prepared under standard conditions with standard composition. From these results it can be seen that both the fractal dimension and the radius of gyration grow during the reaction process. The formed sol consists of very weakly branched polymeric structures with final fractal dimension between 1.3 and 1.5. After cooling the solution, no significant growth takes place within a period of at least 3 days.

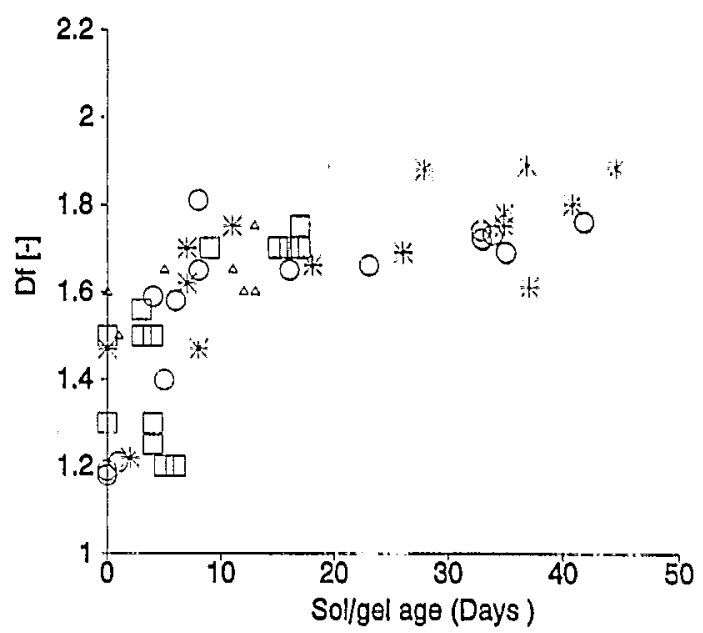

Fig. 4. Evolution of $D_{f}$ as function of sol-gel age for silica samples with standard composition. Data from two measurement sessions using long ( $4 \mathrm{~m}$ (squares, session 1; circles, session 2)) and short $(0.6 \mathrm{~m}$ (triangles, session 1$)$ and $0.7 \mathrm{~m}$ (stars, session 2)) camera length. 
Table 4

Evolution of characteristic parameters during reaction of three silica sols prepared under standard conditions with standard composition

\begin{tabular}{lllll}
\hline & $\begin{array}{l}\text { Reaction } \\
\text { time }(\mathrm{h})\end{array}$ & Sol & & \\
\cline { 2 - 5 } & $\mathrm{A}$ & $\mathrm{B}$ & $\mathrm{C}$ \\
\hline$D_{\mathrm{f}}:$ & 1 & 1.10 & $\mathrm{a}$ & 1.30 \\
& 2 & 1.34 & 1.00 & 1.48 \\
& 3 & 1.47 & 1.30 & 1.55 \\
& $3+X$ & $1.45^{\mathrm{b}}$ & & $1.50^{\mathrm{c}}$ \\
$R_{\mathrm{g}}(\AA):$ & 1 & 9 & $\mathrm{a}$ & \\
& 2 & 11 & 15 & 23 \\
& 3 & 14 & 25 & 22 \\
& $3+X$ & $14^{\mathrm{b}}$ & & $22^{\mathrm{c}}$ \\
\hline
\end{tabular}

a No scattering.

${ }^{\mathrm{b}}$ Sol cooled to room temperature, second measurement after 4 hours $(X=4 \mathrm{~h})$.

c Sol cooled to room temperature, second measurement after 3 days ( $X=3$ days).

\subsubsection{Structural evolution of silica sols during sol aging}

Fractal dimension and radius of gyration of different polymeric sols and gels with standard composition has been analyzed as a function of sol or gel age. In Fig. 3 a SAXS spectrum of a 46-day-old silica sol is shown. The fractal region is clearly present. In Figs. 3 and 4 the evolution of, respectively, the fractal dimension and radius of gyration are shown as function of age. Data obtained with
Table 5

Characteristics of silica sols with non-standard water/alkoxide ratio, $r_{w}$, calculated from SAXS spectra

\begin{tabular}{lllll}
\hline & $r_{\mathrm{w}}$ & $\begin{array}{l}\text { Age } \\
\text { (days) }\end{array}$ & $D_{\mathrm{f}}$ & $R_{\mathrm{g}}(\AA)$ \\
\hline Higher $r_{\mathrm{w}}$ & 12 & 0 & 1.59 & 14 \\
& 12 & 5 & 1.48 & 26 \\
& 8.2 & 0 & 1.41 & 22 \\
& 8.2 & 5 & 1.25 & 20 \\
Standard $r_{\mathrm{w}}$ & $(6.4)$ & $(0)$ & $(\approx 1.4)$ & $(\approx 17)$ \\
Lower $r_{w}$ & 5.5 & 5 & 1.6 & \\
& 4.6 & 0 & 1.0 & 15 \\
& 4.6 & 16 & 1.55 & 24 \\
& 2.2 & 14 & 1.1 & 17 \\
& 1.0 & 0 & $\mathrm{a}$ & $\mathrm{a}$ \\
& 1.0 & 22 & $\mathrm{a}$ & $\mathrm{a}$ \\
\hline
\end{tabular}

a No scattering observed; $D_{\mathrm{f}}$ and $R_{\mathrm{g}}$ cannot be calculated.

both short and long camera length are combined in these figures; the calculated fractal dimensions for a sample from both camera configurations are within the experimental error.

As can be seen from these figures, the increase of sol and gel age results in an increase of both the fractal dimension and the radius of gyration. A transition point at $\approx 10$ days is clearly visible in both figures. This transition corresponds to gelation of the sol, which was found to take place approximately

Table 6

Characteristics of silica sols with non-standard reaction temperature and acid content calculated from SAXS spectra

\begin{tabular}{|c|c|c|c|c|c|}
\hline & $r_{\mathrm{H}+}$ & $r_{w}$ & Age (days) & $D_{\mathrm{f}}$ & $R_{\mathrm{g}}(\AA)$ \\
\hline \multicolumn{6}{|l|}{ Reaction at $80^{\circ} \mathrm{C}$ (standard) } \\
\hline Higher $r_{\mathrm{H}+}$ & 0.096 & 6.3 & 8 & 1.70 & 24 \\
\hline Standard & $(0.085)$ & $(6.4)$ & $(\approx 8)$ & $(\approx 1.6)$ & $(\approx 25)$ \\
\hline Lower $r_{\mathrm{H}+}$ & 0.074 & 6.4 & 8 & 1.7 & 24 \\
\hline Lower $r_{\mathrm{H}}$ & 0.043 & 6.4 & 8 & 1.42 & 22 \\
\hline Standard, no reflux ${ }^{a}$ & 0.085 & 6.4 & 7 & 1.65 & 24 \\
\hline Standard, 2 days open air ${ }^{b}$ & 0.085 & 6.4 & 18 & 1.6 & 24 \\
\hline Standard, dip solution & 0.085 & 6.4 & 40 & $\approx 1.2$ & \\
\hline \multicolumn{6}{|l|}{ Reaction at $20^{\circ} \mathrm{C}$} \\
\hline Standard & 0.085 & 6.4 & 17 & 1.35 & 20 \\
\hline Lower $r_{\mathrm{H}+}$ & 0.043 & 6.4 & 8 & 1.45 & 7 \\
\hline Lower $r_{\mathrm{w}}$ & 0.085 & 1 & 0 & & $\mathrm{c}$ \\
\hline
\end{tabular}

\footnotetext{
The reaction mixture was stirred at $80^{\circ} \mathrm{C}$, in an erlenmeyer without reflux cooler.

${ }^{b}$ A standard polymeric solution was kept in an open bottle at room temperature for 2 days, then the bottle was closed.

${ }^{c}$ No scattering; $D_{\mathrm{f}}$ and $R_{\mathrm{g}}$ cannot be calculated.
} 
7-14 days after synthesis. The development of the viscosity during the process was observed visually.

The fractal dimension directly after sol synthesis is about 1.4 , and increases to $\approx 1.65$ at the gelation point around 10 days. After 20 days, a limiting value of $1.75-1.85$ is reached. The radius of gyration is about $2 \mathrm{~nm}$ directly after the sol synthesis and increases to $\approx 3 \mathrm{~nm}$ around 10 days. The limiting value of $4 \mathrm{~nm}$ is reached after 20 days. From the analysis at high $Q$ in the $\log -\log$ plots, the upper limit of $r_{0}$ of these samples is estimated to be 0.2 nm.

\subsection{Polymeric silica sols with non-standard compo- sitions}

The influence is investigated of reaction temperature, $r_{\mathrm{w}}$, and acid concentration on the structural evolution of silica sols. Sols have been prepared directly preceding the SAXS measurements as well as some days before the measurements. The results have to be compared with standard silica sols of the same age as given in Figs. 3 and 4. Therefore, the calculated fractal dimensions and radii of gyration, as presented in the next tables, are given together with the age of the respective samples. In Table 5, the influence is given of $r_{\mathrm{w}}$ on the fractal dimension and radius of gyration. It is shown that, with the standard composition as basis, an increase of $r_{\mathrm{w}}$ to 12 (standard: $r_{\mathrm{w}}=6.4$ ) does not result in a significant change of the polymeric structure. A decreased $r_{\mathrm{w}}$ compared with the standard composition, however, shows clearly a trend towards smaller cluster sizes and lower fractal dimensions. At $r_{w}=1$ no significant scattering can be detected.

In Table 6, results are given of experiments where reaction temperature and acid content are varied and where the standard composition and temperature is recapitulated for comparison reasons. Standard dip solutions, which are used for membrane modification, are prepared by $18 \times$ dilution with ethanol of a freshly prepared standard $\mathrm{SiO}_{2}$ sol.

The influence of sol concentration during the synthesis was investigated for a sample which was prepared under standard conditions, however, without using a reflux cooler. This results in a decrease of the sol volume during the synthesis of around $20 \%$.
The influence of atmosphere during synthesis and aging on sol structure was investigated by leaving a standard sol open to air for 2 days prior to closure of the sample bottle.

Small angle X-ray scattering spectra have similar shapes as given in Fig. 2. The results, as summarized in Table 6, show the following.

(i) Compared with the standard $\left(r_{\mathrm{H}+}=0.085\right)$, small differences in acid concentration $\left(r_{\mathrm{H}+}=0.096\right.$ and $\mathrm{r}_{\mathrm{H}+}=0.074$ ) do not show a significant difference in polymeric structure, as characterized by the fractal dimension and the radius of gyration.

(ii) Lowering the acid concentration to half the standard amount $\left(r_{\mathrm{H}+}=0.043\right)$ results in lower fractal dimensionality and cluster size (compared with sols prepared with standard composition and of the same age, as can be seen in Figs. 3 and 4).

(iii) A lower temperature, $20^{\circ} \mathrm{C}$ compared with the standard temperature $80^{\circ} \mathrm{C}$, shows a very strong decrease in fractal dimensionality and cluster size. Even for a standard sol 17 days old, a very low fractal dimension of only 1.35 was found, with a small radius of gyration of $2 \mathrm{~nm}$ instead of respectively 0.17 and $3 \mathrm{~nm}$ for the standard sols of this age.

For the sample with $r_{\mathrm{H}+}=0.043$, it can be seen that the fractal dimension is 1.45 . A sol with the same composition, but synthesized at $80^{\circ} \mathrm{C}$, as shown in the same table, gave a fractal dimension of 1.7. Otherwise, it has to be mentioned that the experimental error in the calculated $D_{f}$ is about \pm 0.07 . This error may explain the reverse order of $D_{\mathrm{f}}$ for the samples with $r_{\mathrm{H}+}=0.085$ and $r_{\mathrm{H}+}=0.043 \mathrm{com}$ pared with the experiments at $80^{\circ} \mathrm{C}$.

The sample with lower $r_{w}$ of 1 showed only background scattering; this condition was also observed for the samples with this composition at $80^{\circ} \mathrm{C}$.

(iv) Within the experimental error, there is no effect measured in the experiments where a sol was kept in open air prior to closing the bottle and where no reflux cooler was used. The latter case implies that during the process ethanol is evaporated (volume decrease about 20\%) and thus the dilution is decreased.

(v) The standard $\mathrm{SiO}_{2}$ dip solution, as used for membrane modification, showed a very low fractal dimension of 1.2 even after 40 days. No $R_{\mathrm{g}}$ has been given because the camera configuration for this experiment only covered the high $Q$-range. 
3.3. Polymeric silica / titania, silica / zirconia and silica / alumina sols

Results of SAXS experiments with $\mathrm{SiO}_{2} / \mathrm{TiO}_{2}$, $\mathrm{SiO}_{2} / \mathrm{TiO}_{2}$ and $\mathrm{SiO}_{2} / \mathrm{Al}_{2} \mathrm{O}_{3}$ sols are given in Table 7. The SAXS spectra showed similar shapes to $\mathrm{SiO}_{2}$ sols, which indicates that with these experiments no two-phase system is detected. A single fractal region is present for all the samples. The spectra of a $\mathrm{SiO}_{2} / \mathrm{TiO}_{2}$ and a $\mathrm{SiO}_{2} / \mathrm{ZrO}_{2}$ sample are shown in Figs. 5 and 6 , respectively.

It can be seen that for the binary samples, the single-step prehydrolysis process results in structures too small to be analyzed with SAXS, and only background scattering is observed.

Scattering only occurs for $\mathrm{SiO}_{2} / \mathrm{TiO}_{2}$ samples in the cases that

(i) samples are allowed to age for 1 month (SiTi30), resulting in a very low fractal dimension (1.3) and small cluster size $(1.6 \mathrm{~nm})$, or

(ii) a high $r_{\mathrm{w}}$ of 6.4 is used in the prehydrolysis of TEOS (SiTi10). The sol, however, gelled immediately during the addition of the titanium precursor solution.

Addition of a second amount of water and acid, in the two-step hydrolysis process, results in polymers

Table 7

SAXS results for binary sols

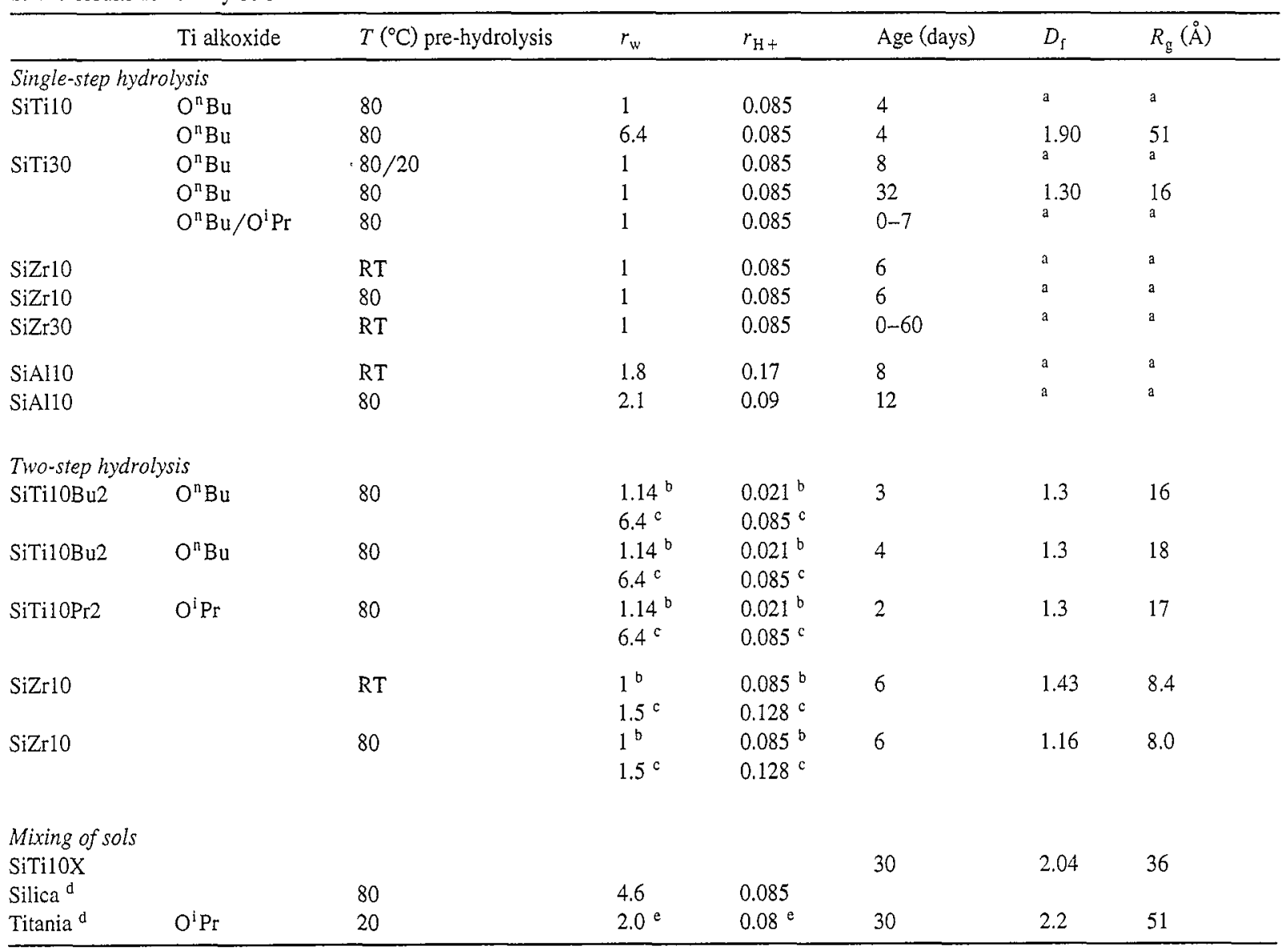

\footnotetext{
${ }^{\text {a }}$ No scattering, $D_{\mathrm{f}}$ and $R_{\mathrm{g}}$ cannot be calculated.

${ }^{b}$ First hydrolysis step.

c Total $r_{\mathrm{w}}$ and $r_{\mathrm{H}}+$ after second hydrolysis step.

'Prehydrolyzed sol used for SiTi10X.

"Molar ratio calculated based on $\mathrm{Ti}\left(\mathrm{O}^{\mathrm{i}} \mathrm{Pr}\right)_{4}$.
} 


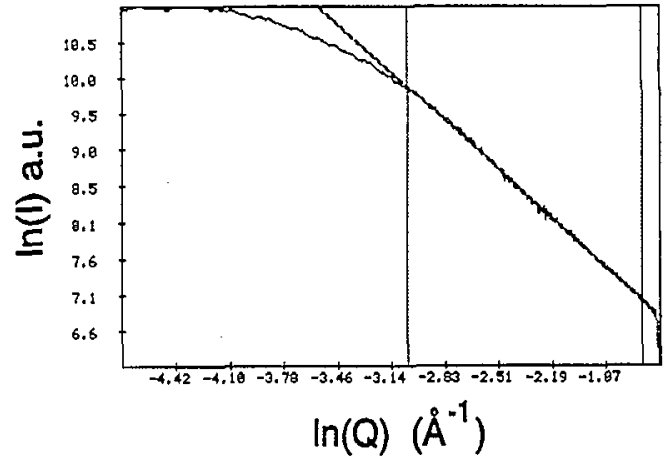

Fig. 5. SAXS spectrum of silica/titania sample SiTiloX with $4 \mathrm{~m}$ camera length. $D_{\mathrm{f}}=2.04 \pm 0.07, R_{\mathrm{g}}=3.6 \pm 0.2 \mathrm{~nm}$.

with a relatively low fractal dimension and small cluster size in the order of 0.13 and $1.7 \mathrm{~nm}$, respectively, for SiTi10 and 0.145 and $0.8 \mathrm{~nm}$, respectively, for SiZr10. It has to be noted that there is no difference, within the experimental error, measured between sols prepared from $\mathrm{Ti}\left(\mathrm{O}^{\mathrm{i}} \mathrm{Pr}\right)_{4}$ compared with $\mathrm{Ti}\left(\mathrm{O}^{\mathrm{n}} \mathrm{Bu}\right)_{4}$ under these conditions.

Prehydrolysis of both TEOS and the titanium isopropoxide results in a sol consisting of clusters of $3.6 \mathrm{~nm}$, with a relatively high fractal dimension of 2.04. The corresponding titania sol showed a cluster size of $5.1 \mathrm{~nm}$ and a fractal dimension of 2.2. The SAXS spectrum of the titania sol showed a good resemblance with the silica spectra.

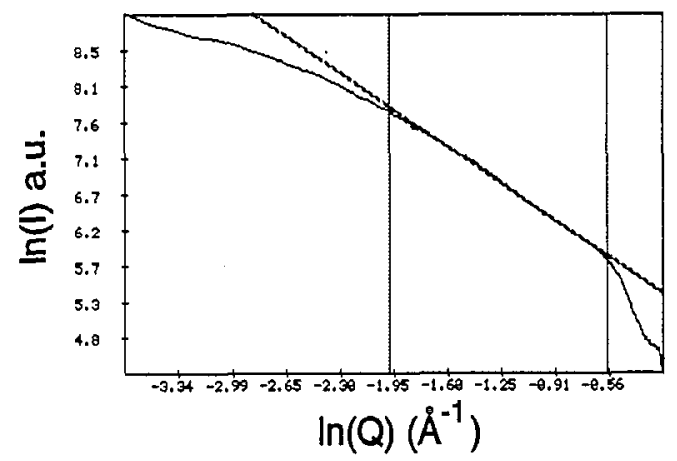

Fig. 6. SAXS spectrum of silica/zirconia sample SiZr10, two-step process, RT two-step hydrolysis. Data obtained with $0.7 \mathrm{~m}$ camera length. $D_{\mathrm{f}}=1.43 \pm 0.07, R_{\mathrm{g}}=0.84 \pm 0.2 \mathrm{~nm}$

\section{Discussion}

\subsection{Polymeric silica sols with standard composition}

\subsubsection{Structural evolution of standard silica sols during synthesis}

At early stages of the hydrolysis and condensation process of silica, no $Q^{-D}$ ( dependency of $I(Q)$ is observed in the spectra. However, as has been explained, this dependence can only be seen if structures have a fractal character. Since this implies self-similarity of the structure, the aggregate size has to be at least a factor 5-10 larger than the primary building unit. The primary building unit has been estimated at $r_{0} \approx 0.2 \mathrm{~nm}$, which is in agreement with comparable small primary building units $\left(r_{0}=0.25\right.$ nm) reported by Ramírez-del-Solar et al. [19] for sol-gel-derived $\mathrm{TiO}_{2}-\mathrm{SiO}_{2}$ sols. The minimum cluster radius which can be measured for our systems is therefore in the order of $1-2 \mathrm{~nm}$.

During the hydrolysis/condensation process, the fractal dimension increases to a maximum value of 1.5 after $3 \mathrm{~h}$ of reaction, which is relatively low and implies that the polymeric structure is very open and only weakly branched. The classical model used to describe aggregation for these conditions is the socalled diffusion-limited cluster-cluster aggregation (DLCCA) model. However, the theoretical fractal dimension, obtained from computer simulations is $D_{\mathrm{f}}=1.78$ [9], and preferential orientation is not taken into account. A model which has a closer resemblance to the physical situation is the tip-to-tip cluster-cluster aggregation process [20], which involves polarization of the clusters when they approach each other. This process results in more linear structures, and consequently a lower fractal dimension $\left(D_{\mathrm{f}}=\right.$ 1.42). This model is therefore more suitable to describe the aggregation under the conditions used.

Lower fractal dimensions compared with the classical aggregation models can also be explained by the more general model for aggregation as proposed by Kallala et al. [10]. This model includes the difference in reactivity of species which have already been reacted, which is the reason that a wide variation in fractal dimensions can be obtained. However, also according to this description, the minimum values of the fractal dimensions we have found are low. 
An important observation of the experiments is that, even with an excess water content $\left(r_{\mathrm{w}}=6.4\right)$ compared with stoichiometric conditions $\left(r_{\mathrm{w}}=2\right)$, a very weakly branched polymer is formed. This observation is supported by results presented by Brinker et al. [5]. The hydrolysis reactions under these conditions go relatively fast to completion, and it is also known that in alcoholic solution the hydrolysis shows an equilibrium leaving a large amount of un-hydrolyzed $\mathrm{Si}-\mathrm{OR}$ groups. This leads to the conclusion that the retarding effect of the partial hydrolysis on further hydrolysis reactions is relatively strong, since no dense or strongly branched structures are formed.

\subsubsection{Structural evolution of silica sols during sol aging}

The two main features of the evolution of $R_{\mathrm{g}}$ and $D_{f}$ as functions of sol and gel age (Figs. 3 and 4) are: (i) a relatively strong increase of fractal dimension and $R_{\mathrm{g}}$ in the first aging period up to the transition point around 7-10 days and (ii) a very weak increase of the fractal dimension and $R_{\mathrm{g}}$ in the second part.

The existence of a transition point can be explained by the fact that gelation of the sols takes place around this time. Gelation can be seen as the point where the polymeric structures contact each other, which results in a large connected structure through the entire volume. This decreases the mobility of the polymers and therefore retards further aggregation. However, the fact that the fractal dimension and $R_{\mathrm{g}}$ do not show a sudden discontinuous change at the sol-gel transition leads to the conclusion that the gelation does not change the structural unit which is determined from SAXS. At the gel point, the number of aggregates (characterized by $R_{\mathrm{g}}$ ) linked together has reached a certain level leading to a string which spans the entire reaction vessel.

The final fractal dimension of $\approx 1.75-1.85$ leads to the conclusion that, for larger clusters, the tip-to-tip model is not valid for describing the aggregation process but diffusion-limited cluster-cluster aggregation is predominant.

\subsection{Polymeric silica sols with non-standard compo- sition}

The increase of $r_{w}$ to 12 compared with a standard value of 6.4 (Table 5) does not have a measur- able influence on $D_{\mathrm{f}}$ and $R_{\mathrm{g}}$. The mechanism of hydrolysis and condensation, which is mainly determined by the $\mathrm{pH}$ of the reaction mixture, is then probably more important than the increase of water content. This suggestion also supports the observation that a $r_{w}$ value of 6.4 , as used in the standard reaction composition, is not an obstruction to form weakly branched polymers if the process is acidcatalyzed. Decreasing of the water content to $r_{\mathrm{w}}=$ 5.5 and 4.6 does not result in a significant change in sol properties if the results in Figs. 3 and 4 are compared. At $r_{\mathrm{w}}=2.2$, however, both $D_{\mathrm{f}}$ and $R_{\mathrm{g}}$ are measurably less than for standard sols with the same age: $D_{\mathrm{f}}=1.1$ compared with about $D_{\mathrm{f}}=1.65$ for the standard and $R_{\mathrm{g}}=1.7 \mathrm{~nm}$ compared with $R_{\mathrm{g}}=3 \mathrm{~nm}$ for the standard. Further lowering to a value of $r_{\mathrm{w}}=1$ showed that no structures are formed in the standard reaction time which show scattering.

Decrease of water concentration results in smaller and more open structures. Two possible causes can be responsible for this: (i) the lower water content results in slower reactions (order of water in hydrolysis reaction is 1), leading to a slower development and growth of the fractal structures, or (ii) when the water content decreased below the stoichiometric value of $r_{\mathrm{w}}=2$, no complete hydrolysis is possible under any condition. This leads to the development of less branched structures.

Possibility (i), however, is less likely if the decrease in reaction rate is high. A strong decrease in reaction rates may ultimately result in reaction limited aggregation (RLCCA), and the corresponding fractal dimensions for this mechanism are higher than for diffusion-limited aggregation. For a small decrease in reaction rates, a gradual increase of fractal dimension can be expected according to the model of Kallala et al. [10].

Slight changes in acid concentration (Table 6) did not influence the aggregation process. A decrease of the acid concentration to half the standard concentration showed that the aggregation is slower; the reported values of $D_{\mathrm{f}}$ and $R_{\mathrm{g}}$ after 8 days $\left(D_{\mathrm{f}}=1.41\right.$ and $R_{\mathrm{g}}=2.2 \mathrm{~nm}$ ) are lower than sols with standard composition at this age $\left(D_{\mathrm{f}}=1.6\right.$ and $R_{\mathrm{g}}=2.5 \mathrm{~nm}$, compared with the help of Figs. 3 and 4). The calculated $\mathrm{pH}$ (measurement of $\mathrm{pH}$ in alcohol/water solutions is not clearly defined [21]) value for this sol, however, is only increased from $0.82\left(r_{\mathrm{H}+}=\right.$ 


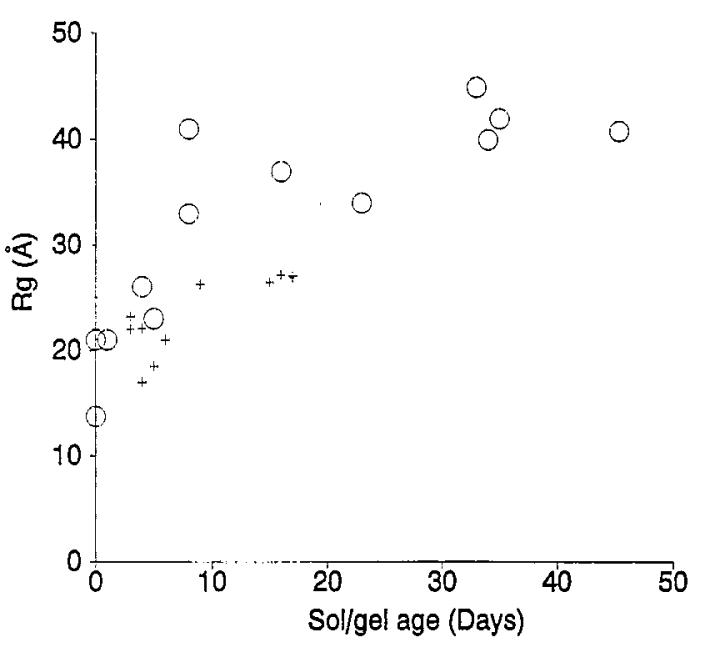

Fig. 7. Evolution of $R_{\mathrm{g}}$ as function of sol-gel age for silica sols with standard composition. Camera length $4 \mathrm{~m}$, data from two measurement sessions (crosses, session 1; circles, session 2).

0.085 , standard $)$ to $1.12\left(r_{\mathrm{H}+}=0.043\right)$, and the isoelectric point of silica $(\mathrm{pH}=2.2[8])$ is not exceeded by this decreased acid concentration. Since this isoelectric point is regarded as the point where acidcatalyzed processes change to base-catalyzed processes [9], the decrease of concentration obviously only decreases the reaction rates; the mechanisms, however, do not change.

Decrease of reaction temperature to room temperature (Table 6) also resulted in decrease of the $D_{\mathrm{f}}$ and $R_{\mathrm{g}}$. For the sol with standard composition, $D_{\mathrm{f}}=1.35$ and $R_{\mathrm{g}}=2 \mathrm{~nm}$, compared with $D_{\mathrm{f}}=1.7$ and $R_{\mathrm{g}}=3 \mathrm{~nm}$ at $80^{\circ} \mathrm{C}$ (taken from Fig. 7). The activation energy for the acid-catalyzed hydrolysis reaction is $\approx 50 \mathrm{~kJ} / \mathrm{mol}$ [22]; the calculated decrease in hydrolysis rate from $80^{\circ} \mathrm{C}$ to $20^{\circ} \mathrm{C}$ is then about 33 times. Since the activation energy for condensation is likely to be higher, this means that the growth of the polymeric structures is slow as well.

The structural evolution of dip solutions (dilution $18 \times$ ) used for membrane modification is very slow. Even after 40 days the fractal dimension is still only 1.2. Since dilution affects both the hydrolysis reaction rates and the condensation reaction rates by a decrease of a factor $18^{2}$ (reaction rates are first order in both components [23]), dilution looks to result in very effective retardation of the growth process.

\subsection{Polymeric binary sols}

Hydrolysis and condensation of the binary sols (Table 7) was performed using very mild conditions, since it is found that these will avoid gelation during the synthesis, which is a prerequisite for membrane formation. These mild conditions were obtained by using low water concentrations and pre-hydrolysis processes.

Single prehydrolysis with a low water content $\left(r_{\mathrm{w}}=1-2.1\right)$ leads to structures which are too small to be detected with SAXS in a period up to 1 week after synthesis. A small fractal dimension (1.3) and small radius of gyration $(1.6 \mathrm{~nm})$ can be measured only after 1 month (SiTi30). The use of a sol with standard water content, used for silica $\left(r_{w}=6.4\right)$, in the prehydrolysis step caused direct gelation during the addition of the titanium precursor. This reaction clearly shows the high reactivity of these precursors. These conditions do not result in a suitable route for preparing sols for membrane modification. The fractal dimension (1.9) and radius of gyration $(5.1 \mathrm{~nm})$ for this gel are relatively high.

However, if a two-step hydrolysis process is used, the addition of a second amount of water and acid after the addition of the titanium precursor to a total water content equal to the above described single-step process (up to $r_{\mathrm{w}}=6.4$ ) did not lead to gelation. The formed sol has a fractal dimension equal to, or even lower than, the standard silica sols $\left(D_{\mathrm{f}}=1.3\right)$. The radius of gyration is also relatively low; $R_{\mathrm{g}} \approx 1.7$ nm.

Binary $\mathrm{SiO}_{2} / \mathrm{ZrO}_{2}$ and $\mathrm{SiO}_{2} / \mathrm{Al}_{2} \mathrm{O}_{3}$ do behave slightly different than $\mathrm{SiO}_{2} / \mathrm{TiO}_{2}$ sols and the main points of the preceding discussion are also valid for these systems. The two-step hydrolysis process for $\mathrm{SiO}_{2} / \mathrm{ZrO}_{2}$ showed that structures are formed with a moderate fractal dimension $\left(D_{\mathrm{f}} \approx 1.45\right)$ and small cluster size $\left(R_{\mathrm{g}} \approx 0.8 \mathrm{~nm}\right)$ using a final $r_{\mathrm{w}}=1.5$. However, the total amount of water for the $\mathrm{SiO}_{2} / \mathrm{TiO}_{2}$ two-step hydrolysis experiment is considerably higher $\left(r_{w}=6.4\right)$ than for the $\mathrm{SiO}_{2} / \mathrm{ZrO}_{2}$ system, while the fractal dimension is slightly lower $\left(D_{\mathrm{f}}=1.3\right)$ and the radius of gyration is larger $\left(R_{\mathrm{g}}=\right.$ $1.7 \mathrm{~nm}$ ). From these results, it looks that the titanium precursor is less reactive than the zirconium alkoxide, since the difference in water content is considerable, while the difference in fractal structure is less. 
These differences must be caused by differences in reactivity of the alkoxides; this can be analyzed according to the partial charge model of Livage et al. [11]. Based on the partial charge of $\mathrm{Zr}(0.65)$ compared with $\mathrm{Ti}(0.63)$ alone, a higher reactivity of zirconium alkoxides can be expected. However, the fact that the zirconium alkoxide is complexed with butanol, and the possibility of oligomerization of the titanium butoxide, which both lead to decrease of reactivity due to the effect of coordination expansion [11], makes a direct comparison difficult.

Also for $\mathrm{SiO}_{2} / \mathrm{Al}_{2} \mathrm{O}_{3}$, the single-step prehydrolysis hydrolysis process leads to very fine structures, which are too small to resolve with SAXS. This smallness is remarkable since the water content in the prehydrolysis process $\left(r_{\mathrm{w}}=1.8\right.$ and 2.1$)$ is relatively high. For $\mathrm{SiO}_{2} / \mathrm{ZrO}_{2}$, in a two-step process which is in principle milder, fractal systems have been obtained using $r_{\mathrm{w}}=1.5$. Obviously, the $\mathrm{Al}$ precursor is less reactive, which is in agreement with the fact that the functionality is low due to the chelate (etac) group.

From Section 3.2. it is known that TEOS prehydrolysis with $r_{w}=1$, leads to structures which are too small to be resolved with SAXS. The addition of the composite alkoxide does not seem to change this situation. This lack of change is an indication that the total amount of free water is negligible and only condensation reactions with hydrolyzed TEOS are possible. However, these do not result in the formation of fractal structures for the conditions in this study.

Also it is known from the experiments with silica that for prehydrolysis conditions at $r_{\mathrm{w}}=6.4$ :

(i) fractal structures are already formed;

(ii) free water is likely to be present, since the excess water is considerable (in stoichiometric conditions $r_{\mathrm{w}}=2$ ). During the addition of, for example, the titanium precursor solution to this highly reactive pre-hydrolyzed silica sol, fast hydrolysis and condensation of the $\mathrm{Ti}$ precursor takes place. Since no precipitation is observed, we conclude that a considerable amount of these condensation reactions also take place with the prehydrolyzed silica. SchramlMarth et al. [24] have prepared $\mathrm{SiO}_{2} / \mathrm{TiO}_{2}(20 \%$ $\mathrm{TiO}_{2}$ ) sols according to this two-step route. This route was the best to prepare homogeneous binary sols, and it was proven, using spectroscopic tech- niques (Raman spectroscopy), that a considerable amount of $\mathrm{Si}-\mathrm{O}-\mathrm{Ti}$ bonds were present.

Our work supports the hypothesis that a homogeneous system is formed in the two-step process by the absence in structure difference between the binary sols prepared with titanium butoxide and titanium propoxide (SiTi10Bu2 and SiTi10Pr2). This absence is remarkable since the latter alkoxide has a much higher reactivity. The formation of homogeneous binary sols can be explained by assuming that the condensation of the titanium precursors on the prehydrolyzed silica is the only possible mechanism and therefore rate determining. Due to the low water content in the prehydrolysis, $r_{w}=1.14$, hydrolysis and condensation of the titanium precursor is initially not possible since no free water is left.

The binary $\mathrm{SiO}_{2} / \mathrm{TiO}_{2}$ sol prepared from two separately hydrolyzed silica and titania sols resulted in a high fractal dimensionality of 2.04 and a radius of gyration of $3.6 \mathrm{~nm}$. If the fractal dimension of the prepared binary sol is compared with the fractal dimension of the prehydrolyzed TEOS $\left(D_{\mathrm{f}}<1.55\right)$ and the prehydrolyzed titanium butoxide $\left(D_{\mathrm{f}}=2.2\right)$, it can be concluded that the measured fractal dimension is probably a feature of the titania sol. The binary sol then consists of a bulk of weakly branched silica containing titania clusters. The spectrum, however, does not indicate the existence of a binary system; a linear fractal region is found. Based on the absence of Si-O-Ti bonds (using Raman spectroscopy), this conclusion was also proposed by Schraml-Marth et al. [24] for a similar experiment.

\subsection{Polymeric sols in relation with microporous membrane formation}

Two main questions arise when the relation between sol structure and membrane formation is discussed. These are as follows.

(1) How critical, in relation to both sol stability and suitability for membrane formation, is the sol synthesis?

(2) Can one predict the final membrane microstructure (porosity, pore size) if information concerning the sol structure $\left(D_{\mathrm{f}}, R_{\mathrm{g}}\right)$ is present?

With regard to point (1), from the results presented in this paper, we conclude that very fine structured sols have been prepared for both silica 
systems as binary systems. There is, however, an important difference between these systems concerning the synthesis conditions.

Within relatively wide limits in $r_{\mathrm{w}}$ and $r_{\mathrm{H}+}$, the sol structure of silica is insensitive to changes in water and acid content, which is in agreement with the fact that the growth process is diffusion limited. This observation is very important from a technological point of view; silica sols can be prepared without having extreme prerequisites such as a completely water-free environment and extreme precautions in handling of TEOS.

On the other hand, the synthesis of the binary systems is more difficult due to the high reactivity of the alkoxides, and the limits between which gelation does not occur are very narrow.

The range in which membranes can be prepared is limited primarily by the possibility to obtain polymeric sols. Systems are not suitable if gelation takes place during the synthesis. A relatively wide range of sol structures $\left(1<D_{\mathrm{f}} \leq 2.04\right.$ ), however, proved to be suitable in the preparation of microporous membranes, as is shown elsewhere $[14,6]$.

With regard to point (2), as discussed above, sols consisting of weakly branched polymers will interpenetrate during consolidation. Therefore, given the measured fractal dimensions and radii of gyration, mesoporous consolidated systems are not to be expected.

The final pore size and porosity of the microporous system, however, depend on the density of the fractal polymer (Eq. (7)), and the tendency of the polymers or particles to interpenetrate (Eq. (8)), which are both related with $R_{\mathrm{g}}$ as well as $D_{\mathrm{f}}$ [25]:

density $\sim$ mass $/$ volume $\sim r^{\left(D_{\mathrm{f}}-3\right)}$,

$M_{1,2}^{\prime} \propto r^{\left(2 D_{1}-3\right)}$.

The tendency to interpenetrate is inversely proportional to the number of intersections, $M_{1,2}$. Low values of $r$ (which are related to $R_{\mathrm{g}}$ ) result in a relative high density of the fractal polymer, but if $D_{\mathrm{f}}<1.5$, in a decreased tendency of the fractal polymers to interpenetrate. Predictions of pore size and porosity are therefore difficult. As mentioned above, micropores are expected, however, if the polymers are extremely small, or a high degree of interpenetration between the polymers occurs during consolidation; the materials may be regarded as dense.

A second aspect which may play a role is the content of organic residues (alkoxy groups and solvent). During calcination, these are eliminated and cracking may create additional porosity.

With the information available from these SAXS experiments alone, and the combination with the theory (Eqs. (7) and (8)), it is therefore difficult to predict the porosity. Moreover, many other parameters during consolidation, such as drying rate, residual sol reactivity [12] and support interaction [26], are of great importance during the formation of films. Microstructural investigations of non-supported membranes are therefore performed to answer these questions. These experiments are described elsewhere $[14,27]$.

\section{Conclusions}

Acid-catalyzed silica sols with the standard composition $\left(r_{\mathrm{w}}=6.4, r_{\mathrm{H}+}=0.085, r_{\text {alcoliol }}=3.8\right)$, as used for membrane formation, consist of weakly branched polymers characterized with $D_{\mathrm{f}} \approx 1.4$ and $R_{\mathrm{g}} \approx 1.8 \mathrm{~nm}$ directly after synthesis. The primary building unit can only be characterized by the maximum diameter of $0.4 \mathrm{~nm}$, which implies that this primary particle is an oligomer containing 5-10 monomers. Initially the aggregation mechanism can be classified as tip-to-tip cluster-cluster aggregation.

Aging of these sols with standard composition results in a continuous growth of the radius of gyration to $4 \mathrm{~nm}$ and an increase of the fractal dimension to $1.75-1.80$ in a period of $\approx 50$ days. The aggregation mechanism under these conditions can be classified as diffusion-limited cluster-cluster aggregation. Gelation, which takes place after $7-14$ days, did not influence the mechanism of the aggregation process but only the rate. From the point of view of membrane formation, gelation is unfavourable, since modification is not possible. Only freshly prepared sols can therefore be used for membrane formation.

Decrease of reaction temperature, water content and acid content in the synthesis of polymeric silica results in decreased hydrolysis and condensation rates. The formed structures are smaller but are 
weakly branched too. A decrease of $r_{\mathrm{w}}$ to 2.2 resulted in $D_{\mathrm{f}}=1.1$ and $R_{\mathrm{g}}=1.7 \mathrm{~nm}$; further decrease of $r_{w}$ to 1 resulted in polymers too small to produce measurable scattering. Under the investigated conditions, no change in mechanism is therefore found, which can be explained by the fact that the aggregation is diffusion controlled.

Binary $\mathrm{SiO}_{2} / \mathrm{TiO}_{2}, \mathrm{SiO}_{2} / \mathrm{ZrO}_{2}$ and $\mathrm{SiO}_{2} / \mathrm{Al}_{2} \mathrm{O}_{3}$ sols, prepared via the single-step prehydrolysis route, with $r_{\mathrm{w}}=1$ in the TEOS prehydrolysis step, consist of polymers with structures too small to be resolved with SAXS. An increased water content $\left(r_{\mathrm{w}}=6.4\right)$ resulted in gelation during the synthesis.

The two-step hydrolysis process for $\mathrm{SiO}_{2} / \mathrm{TiO}_{2}$ and $\mathrm{SiO}_{2} / \mathrm{ZrO}_{2}$ results in low fractal dimensions of around 1.3 and 1.45 , respectively, and gyration radii of around 1.7 and $0.8 \mathrm{~nm}$, respectively. The zirconium alkoxide is probably more reactive compared with the titanium alkoxides since the fractal dimension is higher despite a lower water content for $\mathrm{SiO}_{2} / \mathrm{ZrO}_{2}$.

The general conclusion from these results is that homogeneous polymeric-silica-based binary sols can be made with additions of a second component up to $30 \mathrm{~mol} \%$. Initially, the fractal dimensions are low $(\approx 1.4)$ as are the gyration radii $(\approx 2 \mathrm{~nm})$.

From the results presented in this paper, it is difficult to predict the structure of the consolidated state, which is of interest for microporous membrane formation. Resulting sol reactivity can lead to further condensation during the consolidation process if the evaporation rate is small. It can be expected, however, that these sols will result in microporous systems, but the possibility of dense films cannot be ruled out.

The authors want to express their special thanks to T.P.M. Beelen, W.H. Dokter, H.F. van Garderen and P.W.J.G. Wijnen (Technical University of Eindhoven) and W. Bras (NWO-SERC/SRS, Daresbury) for their kind help and valuable discussions related with SAXS experiments, computer programs and interpretation. A.A. ten Hoeve and P.J.A.M. Blankenvoorde are acknowledged for binary sol preparation. K.-N.P. Kumar and J.M. Züter are acknowledged for their help related with sample preparation and SAXS measurements. G.M.H. van de
Velde, H. Karrenbeld and J. Heezen are acknowledged for their help with data treatment. Shell Research bv, Amsterdam, is acknowledged for general financial support, and NWO, The Hague, is acknowledged for additional financial support for performing the SAXS experiments.

\section{References}

[1] K.S.W. Sing, D.H. Everett, R.A.W. Haul, L. Moscou, R.A Pierotti, J. Rouquérol and T. Siemiewska, Pure Appl. Chem. 57 (1985) 603.

[2] R.J.R. Uhlhorn, K. Keizer and A.J. Burggraaf, J. Membrane Sci. 66 (1992) 271.

[3] S. Kitao, H. Kameda and M. Asaeda, Membrane 15 (1990) 222.

[4] R.S.A. de Lange, J.H.A. Hekkink, K. Keizer and A.J. Burggraaf, in: Better Ceramics through Chemistry V, ed. M.J. Hampden-Smith, W.G. Klemperer and C.J. Brinker, Mater. Res. Symp. Proc., Vol. 271 (Materials Research Society, Pittsburgh, PA, 1992) p. 505.

[5] C.J. Brinker, T.L. Ward, R. Sehgal, N.K. Raman, S.L. Hietala, D.M. Smith, D.-W. Hua and T.J. Headley, J. Membrane Sci. 77 (1993) 165.

[6] R.S.A. de Lange, J.H.A. Hekkink, K. Keizer and A.J. Burggraaf, J. Membrane Sci. 99 (1995) 57.

[7] R.S.A. de Lange, PhD thesis, University of Twente, Enschede (1993).

[8] R.K. Iler, The Chemistry of Silica; Solubility, Polymerization, Colloid and Surface Properties and Biochemistry (Wiley, New York, 1979).

[9] C.J. Brinker and G.W. Scherer, Sol-Gel Science. The Physics and Chemistry of Sol-Gel Processing (Academic Press, San Diego, CA, 1990).

[10] M. Kallala, R. Jullien and B. Cabane, J. Phys. II (Paris) 2 (1992) 7.

[11] J. Livage, M. Henry and C. Sanchez, Prog. Solid State Chem. 18 (1988) 259.

[12] C.J. Brinker, A.J. Hurd, P.R. Schrunk, G.C. Frye and C.S. Ashley, J. Non-Cryst. Solids 147\&148 (1992) 424.

[13] J. Teixara, in: On Growth and Form, ed. H.E. Stanley and N. Ostrowsky (Nijhof, Dordrecht, 1986) p. 145.

[14] R.S.A. de Lange, J.H.A. Hekkink, K. Keizer and A.J. Burggraaf, J. Non-Cryst. Solids (1995) in press.

[15] W. Bras, G.E. Derbyshire, A.J. Ryan, G.R. Mant, A. Felton, R.A. Lewis, C.J. Hall and G.H. Greaves, Nucl. Instr. Meth. A326 (1993) 587.

[16] J.P. Cotton, in: Neutron, X-ray and Light Scattering, ed. P. Lindner and Th. Zemb (Elsevier Science, Amsterdam, 1991) p. 19.

[17] OTOKO computer program, developed by the SRS/Daresbury Laboratories, Daresbury, UK. 
[18] Computers programs SAXSFIT and SAXSFONY, developed by respectively P.W.J.G. Wijnen and H.F. van Garderen, University of Eindhoven.

[19] M. Ramírez-del-Solar, L. Esquivias, A.F. Craievich and J. Zarzycki, J. Non-Cryst. Solids 147\&148 (1992) 206.

[20] R. Jullien, J. Phys. A19 (1986) 2129.

[21] B.K. Coltrain, S.M. Melpolder and J.M. Salva, in: Ultrastructure Processing of Advanced Materials, ed. D.R. Uhlmann and D.R. Ulrich (Wiley, New York, 1992) p. 69.

[22] J.C. Ro and I.J. Chung, J. Non-Cryst. Solids 130 (1989) 26.

[23] R.A. Assink and B.D. Kay, J. Non-Cryst. Solids 99 (1988) 359.
[24] M. Schraml-Marth, K.L. Walther, A. Wokaun, B.E. Handy and A. Baiker, J. Non-Cryst. Solids 143 (1992) 93.

[25] B.B. Mandelbrot, The Fractal Geometry of Nature (Freeman, San Francisco, 1983).

[26] K-N.P. Kumar, thesis, University of Twente, Enschede (1993).

[27] R.S.A. de Lange, K.-N.P. Kumar, J.H.A. Hekkink, G.M.H. van de Velde, K. Keizer, A.J. Burggraaf, W.H. Dokter, H.F. van Garderen and T.P.M. Beelen, J. Sol-Gel Sci. Technol. 2 (1994) 57. 